\title{
TERRITORIALIDADE, IDENTIDADE ÉTNICA E MULTICULTURALISMO: O MOVIMENTO INDÍGENA NA COLÔMBIA
}

\author{
Mauricio Alejandro Diaz ${ }^{1}$
}

RESUMO: O artigo propõe realizar uma aproximação histórica ao moderno movimento indígena na Colômbia e por outro lado conceitual, e discutir as novas formas de representação das lutas pela identidade étnica na década 1990. Procurando uma análise que resgate a produção sócio antropológica daqueles estudos que rompem com o essencialismo do conteúdo e, alcance, ou, se aproximem ao caráter processual e dinâmico da configuração das novas identidades de base étnica na Colômbia no século XX. Nesta configuração está relacionado com a revitalização histórica da memória cultural indígena, sua luta política pela terra, o diálogo interétnico e intercultural e a identificação com o território como lugar de origem e reprodução da cosmovisão indígena. Pois, nos novos discursos de afirmação étnica observamos uma tensão permanente entre o Estado e os territórios indígenas, as políticas multiculturalistas e a interculturalidade das organizações indígenas. No caso colombiano, esta tensão se manifesta em um contexto social de conflito permanente e violência generalizada. Os territórios das comunidades indígenas, têm de conviver com a guerra entre os atores armados e a presença ameaçadora de empresas multinacionais interessadas nos bens ambientais e recursos minerais. O cenário de violência e o não cumprimento dos direitos étnicos são temas que projetam os discurso e ações dos seus dirigentes do movimento indígena colombiano, frente aos dilemas do novo Estado multicultural.

Palavras-chave: Movimento indígena na Colômbia. Território. Interculturalidade. Multiculturalismo.

NHE'E BYKY: ko artigo oñemoag̃ui ojehasa'akue, umi avá apoha Colombia'pe, ha mbaeichapa onhemoi, oñorairõ ojekua'á haguã, mava ha'e, arape 1990. Upeixa onhemopuã

\footnotetext{
${ }^{1}$ Doutorando no Programa de pos-graduação em Historia da Universidade Federal de Espirito Santo, bolsista FAPES. Mestrado em Estudos Latino-Americanos da Universidade Nacional de San Martin. Buenos Aires, Argentina. Teses: INDI WASI. La casa del Sol. Una etnografía sobre Naturaleza y Territorio en el piedemonte Amazónico. 2011. Graduado em Antropologia na Universidade nacional da Colômbia. Faculdade de Ciências Humanas. Teses: A Ecologia Sagrada em Bogotá, os Novos Movimentos Religiosos Urbanos. 2006. Vencedor bolsa de estudos para pesquisa Concurso: "A natureza, sociedade e território na América Latina e no Caribe" Programa de Becas CLACSO-Asdi de promoção de investigação social 2006-2008 pesquisadores da América Latina e do Caribe. Endereço eletrônico: madiazul@gmail.com.
} 
i'arandu akue, oñorairõ yvy'pe, onhemomgueta interetinico, intercultural, oguahe onhepyru akue. Upeixarõ onhorãirõ i'direito pe, ha mbaeichapa oipuakata.

Ayvu nhe'e: Ava apoha Comlombia'pe. Yvyrupi. Interculturalidade. Multiculturalismo.

RESUMEN: El articulo propone realizar una aproximación histórica al moderno movimiento indígena colombiano y por otro lado conceptualizar y discutir las nuevas formas de representación de las luchas por la identidad étnica en la década de 1990. Buscando un análisis que rescate la producción socio antropológica de aquellos estudios que rompen con esencialismos y que alcancen o se aproximen a un carácter procesual y dinámico sobre la configuración de las nuevas identidades de base étnica en Colombia en el siglo XX. Esta nueva configuración tiene que ver con la revitalización histórica de la memoria cultural indígena, la lucha por la tierra, el diálogo interétnico e intercultural, la identificación de un territorio como lugar de origen y reproducción de su cosmovisión. El surgimiento de los nuevos discursos de afirmación étnica observamos una tensión permanente entre el Estado y los territorios indígenas, las políticas multiculturales y las practicas interculturales de las organizaciones indígenas. En el caso colombiano esa tensión se manifiesta en el contexto social de conflicto permanente y violencia. Los territorios indígenas conviven con la guerra entre actores armados y la presencia amenazadora de multinacionales interesadas en bienes ambientales y recursos minero energéticos. Este escenario y el no cumplimiento de los derechos étnicos son temas y preocupaciones que proyectan los discursos de la diligencia indígena frente a los dilemas del nuevo Estado multicultural.

Palabras Clave: Movimiento indígena en la Colombia. Territorio. Interculturalidad. Multiculturalismo

ABSTRACT: The article proposes to make a historical approach to the modern indigenous movement in Colombia, and on the other, conceptual side, to discuss the new forms of representation of the struggles for ethnic identity in the decade 1990. Looking for an analysis that rescues the socio-anthropological production of those studies, which break with the essentialism of content and reach, or approach, the procedural and dynamic character of the configuration of the new ethnic-based identities in Colombia in the $20^{\text {th }}$ century. This configuration is related to the historical revitalization of the indigenous cultural memory, its political struggle for the land, the interethnic and intercultural dialogue and the identification with the territory as place of origin and reproduction of the indigenous worldview. For, in the new discourses of ethnic affirmation, we observe a permanent tension between the State and the indigenous territories, the multiculturalist policies and the interculturality of the indigenous organizations. In the case of Colombia, this tension manifests itself in a social context of permanent conflict and widespread violence. The territories of indigenous communities must coexist with war between armed actors and the threatening presence of multinational corporations interested in environmental goods and mineral resources. The development of violence and non-compliance with ethnic rights are themes that foresee the speeches and actions of its leaders of the Colombian indigenous movement, facing the dilemmas of the new multicultural State.

Keywords: Indigenous movements in Colombia. Territory. Interculturality. Multiculturalism.

\section{Introdução}


"A la constituyente llegamos después de un largo proceso de lucha en el que debimos enfrentar tanto al Estado como a los sectores de derecha e izquierda del país que se negaban a reconocer nuestra existencia y los derechos que tenemos. Por eso, es importante aclarar que nuestros logros en la constituyente no fueron un regalo del gobierno, allí solo recogimos lo que veníamos sembrando a costa de gran dolor, lagrimas, cárcel y muerte de muchos de nuestros mejores dirigentes" Lorenzo Muelas Hurtado. Liderança indígena da Colômbia (2014, p.44).

No início da década de 1990 começou a se visibilizar a construção de um sujeito político e social étnico na América Latina, com formas de fazer política, discursos e reivindicações próprios. Mais nesta mobilização social étnica, particularmente indígena na Colômbia tem sua origem nos anos de 1970 e a maduração e consolidação de suas principais organizações na década de 1980. Para a década de 1990 o significado destas mobilizações e da constituição de um movimento social indígena colombiano é que a ação coletiva dos grupos étnicos que tinham como centro da estratégia política a luta pela terra e autonomia, transformou-se depois na luta pelo reconhecimento da identidade étnica, que se constitui como base da solidariedade grupal e cultural de sua coletividade pela sobrevivência.

Dessa passagem da mobilização indígena na Colômbia, se expressa uma dinâmica na movimentação social em américa latina, mas também em estratégias de negociação, representação e pressão diante das mudanças econômicas e políticas dos Estados latinoamericanos, além das relações com organismos ou organizações internacionais, também chamados de instituições multilaterais (Bengoa, 2000).

A conveção 169 da OIT assinada em 1989 reconhece diante da normatividade internacional aos indígenas como sujeitos de direitos, como membros de uma comunidade nacional, como sujeitos protagonistas das políticas que os afetam. Se reconhece sua maneira direta e particular de se relacionar com o meio ambiente. Se reconhece o território para desenvolver seu projeto de vida. Neste contexto as organizações indígenas conseguiram ampliar sua presença em espaços transnacionais e configurar-se como o principal ator político afinal é do século XX em América latina. O que alguns pesquisadores chamam de o despertar indígena (Bengoa, 2000).

Como assinala o historiador peruano Aníbal Quijano (2001) a crise do desenvolvimentismo, com a desintegração da estrutura produtiva e, consequentemente, das identidades camponesas e de classe que este promovia, significou uma introdução da identidade e uma revalorização de identidades étnicas que nunca se dissolveram completamente. A globalização, com seu novo universo de comunicação e virtualidade, permite que as comunidades indígenas rurais antes isoladas, em meio desta crise das 
identidades de classe possa conectar-se com seus pares indígenas no resto do continente e reconhecer-se dentro de uma história comum de subordinação e dominação à lógica colonial e ao capital.

A correspondente crise da esquerda favoreceu ainda mais a destruição desta memória e desta identidade como percussores da ação política (QUIJANO, 2001). Tampouco pode-se desconhecer a influência da dupla transição na região: tanto de regimes autoritários a democracias emergentes, como de uma limitada economia desenvolvimentistas a um modelo neoliberal. Assim, América Latina é protagonista da emergência das "novas etnicidades" que se caracterizam pelo uso estratégico e pela reinvenção da etnicidade dos povos indígenas na luta política. O mais interessante é que este processo se fundamenta numa renovada visibilidade do movimento indígena e um protagonismo político inusitado. Neste contexto é imprescindível estudar as particularidades do movimento indígena na Colômbia.

\section{O Movimento indígena Colombiano}

O Movimento Indígena Colombiano (MIC) foi fundado, principalmente, em um contexto de defesa e luta pela terra e tem como epicentro a região do Cauca, ao sul oriental do país, nos Andes colombianos. Durante o período que se conheceu como Frente Nacional $(1958-1974)^{2}$ e por meio da disposição da Lei 135 de 1961 que buscou uma saída às problemáticas rurais através de uma reforma agrária, se geraram conflitos regionais pela propriedade da terra. Este contexto permitiu que em 1968 se constituísse a Asociación Nacional de Usuarios Campesinos (ANUC), permitindo que numeráveis organizações tanto camponesas como de sindicatos agrários se estabelecessem num mesmo espaço de representação. Este despertar e união de setores populares estava organizado em torno da luta pelo acesso à terra e melhores condições de trabalho para o campesinato (Archila, 2008).

\footnotetext{
2 A Frente Nacional foi uma coalizão política estabelecida em 1958 entre o Partido Liberal e o Partido Conservador da República da Colômbia. A modo de respostas diante da chegada da ditadura militar em 1953, sua consolidação no poder entre 1954 e 1956 e depois de uma década de grandes índices de violência e enfrentamentos políticos radicais, os representantes de ambos partidos, Alberto Lleras Camargo (Partido Liberal) e Laureano Gómez Castro (Partido Conservador) se reuniram para discutir a necessidade de um pacto entre ambos partidos para restaurar a presença do Bipartidarismo no poder. No dia 24 de julho de 1956, os líderes assinaram o Pacto de Benidorm, em terras espanholas, onde se estabeleceu como sistema de governo que, durante os 16 anos seguintes, o poder presidencial se alternaria a cada quatro anos, entre um representante liberal e um conservador. O acordo começou a ser aplicado em 1958, logo após a queda de Gustavo Rojas Pinnilla, a transição política efetuada por uma Junta Militar, e com a eleição de Alberto LLeras Camargo, e chegou a seu fim em 7 de agosto de 1974, no momento em que termina o mandato do político conservador Misael Pastrana Borrero. O período frente nacionalista significou uma espécie de ditadura feita pelos partidos mais tradicionais da Colômbia liberal e conservador perpetuando o clientelismo e a exclusão política. VAZQUEZ CARRIZOSA, Alfredo. Historia critica del Frente Nacional. Bogotá: Ediciones Foro Nacional por Colombia: 1992. p. 63111.
} 
Nesse contexto, a recuperação da terra se converte num tema central da luta indígena e camponesa, ainda que no caso indígena esta luta remonte às ocupações de fazendas lideradas por Manuel Quintín Lame e José Gonzalo Sánchez importantes lideranças indígenas nas décadas de 1920 e 1930 na região chamada do Grande Cauca. ${ }^{3}$ Além disso, na década de 1970 emergiria o Conselho Regional Indígena do Cauca (CRIC) como organização particularmente indígena, distanciando-se das organizações camponesas e operárias (ARCHILA, 2010)

No começo dos anos 1970, com a emergência do CRIC e seu distanciamento das organizações camponesas, principalmente da ANUC, se impulsiona a luta pela terra desde a identidade étnica e mais além da identidade de classe, associada à luta camponesa e operária. Isso é acompanhado pela denúncia das comunidades frente à violência contra os indígenas. Estas reivindicações e denúncias sobre a violação dos direitos humanos faz com que o movimento indígena alcance o contexto internacional. Para Archila (2010) quando se apresenta este despertar da luta indígena desde o reconhecimento, ressignificação e autonomia étnica ${ }^{4}$, ou seja, além de apenas recuperação da terra, se apresenta uma mudança dentro do movimento que é passar de uma posição de classe a uma posição de pertencimento desde o étnico. Segundo o historiador e sociólogo colombiano, isso possibilitou que as organizações indígenas emergentes posteriormente nos anos de 1980 pensem e definam uma identidade mais ligada ao étnico e a suas próprias manifestações culturais. Na década de 1980 o MIC logra consolidar-se em um contexto histórico de repressão generalizada a mobilização social ${ }^{5}$, um projeto político de unidade, intercultural e inter étnico pela defesa dos avanços feitos na anterior década em matéria de recuperação de terras e autonomia, nascendo a Organização

\footnotetext{
${ }^{3}$ Segundo Archila esta luta pela terra no Cauca, conhecida como "quintinadas" possibilita o surgimento do que hoje se conhece como movimento indígena na Colômbia. ARCHILA NEIRA, Mauricio; GONZÁLEZ PIÑEROS, Nidia Catherine. Movimiento indígena Caucano: Historia y política. Tunja: Editorial Universidad Santo Tomas, 2010. p.86.
}

4 A autonomia, corresponde à ideia de exercer o governo próprio em seus territórios. A capacidade de administrar e organizar sua vida econômica e social de acordo com suas necessidades e padrões culturais, frente aos processos de integração da Nação colombiana. In ANDRADE, Luis Evelis. 25 años de la ONIC, un legado vivo de la resistencia indígena en Colombia. In: Revista Observatorio étnico Cecoin, Bogotá, agosto 2007. p 12-32.

${ }^{5}$ Para Caviedes, as denúncias de violações dos direitos políticos e civis dos povos indígenas aumentam em 1978. As denúncias registradas na época, por meio de revisão na imprensa nacional e regional, demonstram que o autor fundamental destas violações é o Estado colombiano. Ainda que este pico de 1978 não volta a se repetir nos quatro anos seguintes, o número de denúncias feitas pelas organizações indígenas entre 1979 e 1982 (através do órgão que então denunciava em nome das comunidades de todo o país, o jornal Unidad Indígena, que se pública desde 1974) se mantém em quase o dobro da média dos anos anteriores a 1978. CAVIEDES, Mauricio. El surgimiento de la Organización Nacional Indígena de Colombia, ONIC en el período de gobierno de Julio César Turbay (1978-1982). In: Colombia Etnias Y Política. Revista Del Observatorio Indígena De Políticas Públicas De Desarrollo Y Derechos Étnicos. Siglo Del Hombre Bogotá. V.4 fasc.1 2007. p.142 - 159. 
Nacional indígena da Colômbia (ONIC) ${ }^{6}$. A fundação da ONIC foi resultado de processos de reorganização e amplitude autônoma do MIC, e iniciado pelo CRIC, modelo das organizações indígenas modernas na década de 1970. Assim se reuniram alguns líderes das organizações de diversos tipos e povos indígenas (Arhuaco, Kogui, Sikuani, Emberá, Cañamomo, Pijao, Pastos e tribos amazônicas, com os indígenas caucanos - Nasa, Coconucos e Guambianos Misak). Nestes líderes e vozeiros buscavam dar uma identidade mais sólida a diversas reivindicações e proteger os logros e demandas pela construção de uma territorialidade étnica e autônoma.

No início dos anos 1990 em um contexto internacional caracterizado pela ascensão da etnicidade e pelo surgimento de marcos teóricos que defendem o direito à diferença, a democracia e os direitos das minorias sociais; Além, de um contexto político nacional em permanente crises de legitimidade que abougava pela participação política de outros setores sociais antes excluídos como possibilidade para a refundação de um Estado social de direitos, gerou um cenário político favorável às demandas de caráter étnico na Colômbia. A participação na Assembleia Nacional Constituinte (ANC) de 1990, na qual foi expedida a Constituição Política (CP) de 1991 foi talvez o feito mais importante da história do Movimento Indígena Colombiano (MIC). Pela primeira vez na história da Colômbia, os dirigentes indígenas participaram da criação de uma constituinte ao liderar não só as demandas das comunidades e organizações indígenas, mas também a de outros setores étnicos, sociais e populares da Colômbia. Os constituintes indígenas eleitos foram: Lorenzo Muelas Hortado, da comunidade indígena caucana Misak; Francisco Rojas Birry, pertencente à comunidade Emberá no pacífico colombiano; além de Alonzo Guzmán, em representação do Movimento Armado Quintín Lame, recentemente desmobilizado. Num contexto particular de abertura democrática e econômica do Estado, o MIC conseguiu dar continuidade à luta indígena, desta vez no marco de uma constituinte que se marcava como carta de salvação para a crise de legitimidade do Estado $^{7}$

\footnotetext{
${ }^{6}$ Em outubro de 1980, na comunidade Lomas de Llarco do município de Coyaima, no estado de Tolima, se realizou pela primeira vez o "Primeiro Encontro Nacional Indígena da Colômbia". Na assembleia geral decidiram realizar a criação da "Coordenação Nacional Indígena da Colômbia", que tinha como função a organização e convocação do próximo congresso. Assim, em fevereiro de 1982, aconteceria o "Segundo Congresso Nacional Indígena", realizado em Bosa, no estado da Cundinamarca, onde foi fundada a Organização Nacional Indígena da Colômbia, com a participação de 1.500 delegados de diversos grupos étnicos do país. A ONIC se constituiu como autoridade nacional de governo indígena, sobre a comemoração de 30 anos de sua criação em 1982. ANDRADE, Luis Evelis. 25 años de la ONIC, un legado vivo de la resistencia indígena en Colombia. In: Revista Observatorio étnico Cecoin, Bogotá, agosto 2007. p 12-32.

7 A Constituição de 1991 introduziu uma reconfiguração do Estado-nação e registrou cinco mudanças significativas: 1) de um Estado de direito ao Estado social de direito; 2) o reconhecimento dos povos indígenas, 


\section{Identidade étnica politizada}

Os movimentos sociais e a mobilização na Colômbia experimentaram mudanças que dão conta da resposta às conjunturas sociais e políticas, e da incorporação na leitura da mobilização social de enfoques que vão além da identificação com os elementos exclusivamente materiais e de classe das lutas sociais. Este é o caso do MIC. De serem atores definidos pelo pertencimento a uma classe dada por sua relação com a produção e o capital "camponeses" a serem atores políticos definidos por elementos culturais identitários. Para o sociólogo francês Gros (1991) depois do relativo sucesso na recuperação de terras nos anos de 1970, o movimento indígena colombiano vai construir um discurso político fundamentado na identidade.

A construção deste discurso se dá na disputa de visões sobre seu ser, sua luta e suas ações. Os indígenas nascem como atores no seio do movimento camponês, mas rapidamente se definem como não exclusivamente camponeses. Vão demandar terras para si, mas não como fator de enriquecimento e como instrumento para a exploração e a produção. Apelam a uma relação com a terra vista como território para a consolidação de sua cultura e sustentação da mesma. Tomam distância do discurso classista e se voltam a reivindicações culturais. A construção deste discurso politizador da diferença e a maneira de colocá-lo em diálogo com outros atores do movimento social vão gerar momentos de crise, mas também momentos de fortalecimento da identidade do movimento indígena. Para Gros, o processo de consolidação do movimento indígena vai se construir desde a instrumentalização da etnicidade e da consolidação de uma identidade positiva do ser do indígena, no momento em que as demandas indígenas se expressam com força as sociedades latino-americanas se encontram em uma transição do Estado desenvolvimentista, sob o modelo "nacional-populista" que cimentou a identidade nacional com base no desenvolvimento e mestiçagem, ao Estado neoliberal, por uma parte, e dos regimes autoritários, no marco da intensificação do processo de globalização e inserção de temas como o meio ambiente e os direitos das minorias na agenda pública internacional (Gros, 2010, p.135)

Neste eixo tende a um enfoque estadocêntrico e estruturalista que, talvez, descuide de outros aspectos explicativos do movimento indígena colombiano. Se expressa uma certa

enquanto sujeitos coletivos de direito; 3) reconhecimento constitucional de um Estado multicultural e pluriétnico, no que implica na valorização de outras culturas e de caracterizações distintas acerca da propriedade, da família, da religião, da saúde e da natureza, entre outros; 4) a obrigação estatal de oferecer aos indígenas um tratamento diferenciado que potencialize sua diferença, etnicidade e cultura; 5) ação de tutela, que como nova ferramenta jurídica, pretende proteger os direitos fundamentais dos indígenas, enquanto indivíduos e povos. 
“antropomorfização" do Estado, em que pese revesti-lo de uma espécie de vontade, aparece como um ente neutro, à margem dos interesses de atores externos e internos, como os grandes donos de terra na Colômbia, é isso que permite a Gros (1991) sugerir que finalmente o Estado consegue tornar as demandas dos indígenas funcionais para criar legitimidade e governabilidade mediante um "governo indireto" com o qual reafirma uma visão estruturalista do problema.

Uma crítica que se pode fazer à visão de Gros é que perde de vista a disputa de interesses representados em alianças e atores concretos e locais que se produz tanto ao interior do Estado como no âmbito político e social mais amplo em torno às reivindicações indígenas. A questão é que esta visão percebe as organizações como passivas, simplesmente receptoras da política estatal.

Enquanto Gros trata de compreender como os discursos étnicos se desenvolvem em novos cenários políticos, onde a politização da identidade tem um caráter fundamental na conformação e desenvolvimento dos mesmos. A proposta da antropóloga Joanne Rappaport, que mais do que preocupar-se com a questão da identidade em termos essencialistas ou produzida pelo Estado, a concebe como uma estratégia política das organizações indígenas (2001). Rappaport, com sua experiência etnológica no Cauca, pensa a identidade indígena Nasa não como algo homogêneo e sim como algo heterogêneo, em contínua definição. E por outro lado, como uma estratégia política frente aos discursos homogeneizadores provenientes do Estado e ou de fora. A tese da antropóloga Joanne Rappaport nasce de seu estudo etnográfico sobre os indígenas Nasa, nos Andes colombianos, realizando um trabalho etnohistórico e colaborando com o CRIC no programa de educação bilíngue. É verdade, como sustenta Gros, que a identidade indígena é uma construção sócio-histórica (2010). E que o fator importante de mobilização será a reinvenção da identidade étnica, diminuída pela discriminação e pela construção da inferioridade operada desde o paradigma da nação mestiça. Esta identidade étnica vai apelar a elementos de memória que vão ser reconstruídos e reinventados para oferecer um arraigo que potencialize a luta. Não só as figuras dos heróis indígenas, mas também os tipos de organização tradicional como o resguardo e o cabildo ${ }^{8}$,

\footnotetext{
${ }^{8}$ A figura do Resguardo se refere a titulações coletivas de terra pertencentes a comunidades indígenas administradas por suas autoridades e legalizadas e autorizadas pelo Estado. O Cabildo é a Autoridade indígena encarregada de administrar o Resguardo. O artigo 63 da Constituição de 1991 reconhece e regulamenta o direito à propriedade coletiva das terras indígenas e se consideram terras inalienáveis, imprescindíveis e não embargáveis. Nestas figuras provém desde a época colonial, e a história de sua apropriação por parte do movimento indígena colombiano é um dos pontos chave para entender as lutas indígenas pela terra na Colômbia durante o século XX. HERREÑO, Ángel. Evolución política y legal del concepto de territorio ancestral indígena en Colombia. Revista El otro derecho, Bogotá, n.32, p. 255, agt. /set. 2004.
} 
vão ser a base da nova organização que se mobiliza num primeiro momento em torno da recuperação da terra como base material para a construção de um território que aporte uma cultura própria, uma língua própria e uma história própria. A recuperação de terras se converte na forma de resistência a sua dissolução étnica e cultural e por isso a importância da construção do território e territorialidades. Mais o que também alimenta a força das lutas indígenas pela terra é que sua terra, mais do que terra, é "território", não só em termos administrativos (o resguardo), não só em autonomia política e legal (o cabildo) mas também e mais ainda enquanto identidade, a identidade indígena se alimenta do território. O território é parte da identidade entre os indígenas. Então, para o movimento indígena há uma relação íntima entre o Território e Identidade.

\section{Terra, Território e Territorialidade.}

Para responder a esta questão analisaremos dois aspectos: Por um lado, as noções de território cultural e etnicidade ou identidade étnica e o debate entre o multiculturalismo e a interculturalidade com debate teórico que permite sustentar um Estado que reconhece e outorga direitos diferenciados aos "grupos étnicos", entre eles os direitos coletivos, tal como o direito fundamental dos povos indígenas à propriedade coletiva e à autonomia ou autodeterminação. $\mathrm{O}$ fato de que as comunidades indígenas lutem por um território denota uma importância particular do mesmo. É por isso que é necessário precisar os conceitos de territórios e territorialidade.

O território constitui um conceito (teórico) e um objeto empírico de natureza interdisciplinar, é multidimensional e polissêmico. Para Delgado (2003) o território é o cenário das relações sociais e não somente o marco espacial que delimita o domínio soberano de um Estado o conceito de território é mais que uma entidade jurídica, mais que o enraizamento das pessoas a um lugar, mais que os vínculos dos cidadãos a um bairro urbano, e mais que os lugares frequentados pelos indivíduos, pois o território tem aspectos relevantes: o sentimento de pertencimento dos indivíduos e apropriação. Então o território é a expressão ao mesmo tempo material e subjetiva, real e simbólica, de espacialidade das relações que se tecem desde as pessoas- individual ou coletivamente- e como produto das múltiplas interações sociais, políticas, econômicas, culturais que se dão na cotidianidade.

As reivindicações dos indígenas por um determinado espaço geográfico, se construíram em torno do conceito de território, mais especificamente de território cultural, ou seja, aquele espaço ocupado, apropriado e significado por uma determinada comunidade ou 
povo, dentro do qual se desenvolve um mundo de relações vitais com sentido definido "cosmovisão", que são essenciais para sua existência como conglomerado humano. Por isso, é notório Delgado afirmar como a categoria de território se refere à ideia de "a terra que pertence a alguém", então o conceito tem de fundo um sentido de "apropriação cultural" (DELGADO,2001. p.125). Nesta lógica, a noção de território das comunidades indígenas vai além do espaço geográfico ocupado e é mais transcendente que um mero meio de produção, como bem descreve o antropólogo Luis Guillermo Vasco:

\begin{abstract}
Éste abarca el conjunto de muy diversas relaciones mediante las cuales se apropian, utilizan y piensan dicho espacio. Se trata entonces de un territorio definido por formas de ocupación y poblamiento, modos de apropiación a través de formas de trabajo, autoridad y pensamiento, actividades que sobre él se desarrollan, modalidades de recorrerlo, creencias y concepciones asociadas, todo ello constituye ese vasto conglomerado de relaciones sociales que hacen de un espacio sobre la tierra, el territorio de una sociedad en un momento de su historia, siendo éste uno de los elementos básicos de su identidad. Ello explica cómo los indígenas no luchan por un pedazo de tierra, sino que reivindican su tierra, como espacio específico que constituye su territorio y la raíz de su existencia, con la cual se han relacionado históricamente (VASCO 2002, p 204)
\end{abstract}

Assim, o território se vincula estreitamente com as estratégias políticas dos movimentos indígenas, e é neste âmbito em que se fala de territorialidade, no marco das demandas indígenas pela terra. Trata-se de um processo ativo, uma dinâmica de apropriação simbólica e material em um processo histórico determinado. A territorialidade se conforma a partir de relações sociais entre distintos atores, que são mediatizados pelo território. Mas essas relações se complexificam quando as territorialidades de um grupo se interceptam com as de outros grupos. É então este enfoque o ponto de partida para compreender a construção da territorialidade indígena e os conflitos com outros atores interessados nesta, o que supõe um choque entre diferentes territorialidades.

A pregunta pelo território cultural e a territorialidade nos remete necessariamente a um debate mais amplo sobre o multiculturalismo e a interculturalidade. Como propõe Borrero (2010), de onde nasce a preocupação pelos direitos (neste caso, os territoriais) que as comunidades específicas podem ter em razão de seu pertencimento étnico? Em outras palavras, por que devemos reconhecer estas particularidades culturais? O que estaria então no fundo da discussão é "a resistência a que uma só cultura, a liberal ocidental, seja protegida" de modo que todas as outras culturas sigam necessariamente seu caminho.

\title{
5. Etnicidade e Relações Interétnicas.
}

Como indica Eduardo Restrepo em sua cartografia sobre as teorias e definições téoricas do conceito de etnicidade, este projeto propõe uma mirada relacional y não 
ontológica da categoria etnicidade, construída no movimento indígena colombiano, especificamente expressado desde suas organizações:

\begin{abstract}
De esta manera la etnicidad estaría asociada a un ejercicio de definición de categorías étnicas desde una posición relacional. Para estos autores la etnicidad implica un encuadre relacional de identidad y diferencia más que la manifestación de un inmanente ser biológico o cultural... Esta tendencia aborda la etnicidad como un fenómeno intersubjetivo con efectos en las relaciones y prácticas sociales; es entendida, además, como un hecho objetivo que existe en el mundo exterior, independientemente de las categorías analíticas de quien la estudia. En general esta tendencia se asocia al formalismo y, en algunos casos, al estructuralismo" (RESTREPO, 2004, p.17) .
\end{abstract}

No contexto dos movimentos indígenas na Colômbia e especificamente no período que abarca o processo de formação e consolidação do Estado-nação, poderíamos representar ao menos provisoriamente a etnicidade como as estratégias desenvolvidas por distintos grupos étnicos envolvidos na problemática da territorialidade, como espaço de produção e reprodução da vida e a luta pela sobrevivência, quer dizer como uma fronteira cultural. $\mathrm{O}$ antropólogo norueguês Fredrik Barth afirma que:

\begin{abstract}
los grupos étnicos no se distinguen uno de otro a partir de una colectividad cerrada y particular de aspectos culturales, sino que, por el contrario, estos aspectos se movilizan, se desplazan, se marcan o se retraen en situaciones de relaciones de interacción social. Es por esto, que entiende, que la historia de la cultura de un grupo étnico, aunque no se puede conocer independientemente de lo anterior, tiene un devenir propio, rasgos o aspectos que no se desarrollan en forma acumulativa sino cualitativa que provocan la variación y / o la inversión de los rasgos, que pueden permanecer en lo visible o en lo oculto. No es una exposición permanente de rasgos culturales" (BARTH, 1976, p.53).
\end{abstract}

É interessante observar o pensamento de Barth e com alusão a luta do MIC e às organizações indígenas na Colômbia, onde a dinâmica e a interação com outros grupos étnicos são referências chaves para as lutas sociais que realizam. Uma das formas de organização do MIC tem sido a integração de diferentes etnias correspondentes a diferentes territórios andinos, selváticos e do Pacífico colombiano, esta política de integralidade, tal como define o movimento, tem suas práxis política num diálogo de saberes que às vezes questiona e outras vezes legitimam as políticas públicas que o Estado produz para os grupos étnicos da Colômbia. Barth assinala que os atores utilizam as identidades étnicas para categorizar-se a si mesmas e aos outros, com fins de interação (1976). Neste sentido consideramos que os valores culturais e de identificação não estão determinados ou limitados pelos traços culturais primordiais, mas sim orientadas por relações Inter étnica. Esta apreciação permite dar conta das possibilidades individuais no coletivo de criatividade, de seleção de preferência e de opção das referências identitárias e, sobretudo, de estratégias 
políticas, porque estas produções não são ontológicas e sim produto da interação com os “outros”. Uma interação que no caso de América latina foi baseado na Colonialidade.

Para o historiador peruano Aníbal Quijano (2000) a consolidação da Europa como centro de poder mundial está associada à constituição da América e do capitalismo colonial/moderno e eurocentrado como novo padrão de poder mundial. Esta consolidação se baseou em dois processos históricos: a codificação das diferenças entre conquistadores e conquistados a partir da ideia de raça; e a articulação das formas históricas de controle do trabalho, de seus recursos e seus produtos em torno do capital e do mercado mundial. O lugar ocupado pela Europa em relação a esses dois processos permite uma racionalidade específica deste novo padrão de poder: O eurocentrismo. A experiência histórica das sociedades latinoamericanas foi construída a partir desta experiência de colonialidade.

Nesse sentido, Quijano analisa como durante o período colonial se estabeleceu uma divisão racial do trabalho em "o controle de uma forma específica de trabalho podia ser ao mesmo tempo o controle de um grupo específico de gente dominada" (QUIJANO,2000, p, 201). A encomenda (para os índios) e a escravização (para os afrodescendentes) ilustram a forma como se estabeleceu uma tecnologia de dominação/exploração (raça/trabalho) que manteve sua vigência sob novas formas até o final do século XX. Figuras como o resguardo e o cabildo, por exemplo, buscaram garantir a sedentarizarão dos indígenas com disponibilidade de mão de obra para as fazendas dos espanhóis.

Desde o surgimento dos Estados-nação até hoje, os países tiveram diferentes aproximações ao tratamento das populações indígenas americanas e seu território. É assim que durante o século XIX e início do século XX imperou o denominado modelo assimilacionista, que buscava integrar os indígenas à civilização e isso aconteceu tanto no caso da Colômbia como na região latino-americana. O objetivo deste modelo era a dissolução das identidades diferenciadas. É assim que este tipo de ideologia e de prática não tolerava a existência de modelos distintos de vida coletiva. Em lugar de impor ao outro que viva segregado do modelo cultural dominante, necessita que este se insira de uma forma subordinada no tecido das novas relações sociais regidas pelas leis do mercado. O modelo da modernidade, a princípios do século XX fundamentado na correspondência entre um Estado e uma cultura nacional, foi questionado pela realidade de uma diversidade nacional e cultural que coexiste no interior dos Estados-nação (BORRERO, 2010). Como resposta a isso, se formularam ao menos duas propostas que adquiriram especial importância nos discursos políticos e institucionais: o multiculturalismo e a interculturalidade. 
É assim que durante as últimas três décadas, com as reformas constitucionais vários estados latino-americanos adotaram definições e mecanismos próprios do chamado "modelo multicultural", que busca fazer coincidir os direitos especiais em função de grupo com a tradição liberal, de igualdade, universalista. Por outro lado, uma aposta mais crítica tenta mostrar um novo modelo emancipatório em que o reconhecimento de direitos diferenciados transformaria a concepção sobre a hegemonia liberal ocidental. Esta seria a aposta do modelo intercultural materializado num Estado plurinacional.

Em quanto ao modelo multicultural, Cruz (2013) expõe que este teve seus inícios nos anos setenta, principalmente no Canadá, diante da coexistência de várias nações no interior do Estado, foi o produto de uma posição contestadora dos movimentos sociais a respeito do projeto de integração nacional. Assim surge o modelo multicultural que pretende conciliar o modelo democrático e liberal com as exigências próprias da diversidade cultural. Entre seus principais teóricos se poderia mencionar Charles Taylor e Will Kymlicka com seu texto a cidadania multicultural.

A crítica intercultural concebe o multiculturalismo como mais uma estratégia de assimilação cultural, que pretende colocar num mesmo nível as relações de poder entre culturas dominantes e subalternas: "por trás dos direitos étnicos assim reconhecidos se esconderia um propósito homogeneizador por parte do liberalismo, que os outorga como uma forma mais de fazer extensivos seus princípios e formas de ver a vida" (WALSH, 2007.p55)

Walsh considera que o multiculturalismo na América Latina terminou servindo aos interesses do neoliberalismo. De maneira que a interculturalidade busca reconstruir os direitos desde outro paradigma, em particular advogando pela descolonização dos discursos culturais e da formulação de políticas culturais decoloniais.

Em tal medida, a interculturalidade significa "o contato e intercâmbio entre culturas em termos equitativos; em condições de igualdade", ou, da mesma maneira, "um interpensamento e inter-relacionamento que não tem a pretensão de assumir a perspectiva do outro e sim de permitir que a diferença intervenha, abrindo assim novas perspectivas interculturais de viver 'com' ou 'con-viver"' (WALSH, 2007.p.57). As experiências do Equador e da Bolívia, por exemplo, são catalogadas como manifestação de um modelo intercultural que dá lugar a um Estado Plurinacional que tem, no conceito da autora, um marcado sentido político de refundação do Estado a partir de um constitucionalismo de baixo e formulado desde o Sul. 
Por outro lado, Jaramillo (2011) argumenta que no caso colombiano a interculturalidade não somente se refere a um discurso, mas, tem sido uma prática sócio histórica que define a etnicidade e a convivência dos grupos étnicos na diversidade da paisagem cultural colombiana. Os territórios ou espaços interculturais, por exemplo, são lugares habitados por indígenas, camponeses, negros, etc. Mas estes grupos se declaram diferentes em relação com os outros e idêntico em relação a si mesmos. Mais do que um discurso político, o autor entende isso como uma dinâmica de interação interétnica, num marco de condições e negociações com o Estado Plurinacional, ou seja, a interculturalidade poderia ser pensada como uma práxis política, pois, nela se apresentam intercâmbios de linguagens, saberes, visões e representações das diferentes etnias que compõem, por exemplo, a ONIC. Embora este intercâmbio esteja em permanente tensão com as políticas públicas e sociais que criaram o Estado Moderno.

A interculturalidade é uma produção sócio histórica, mas também uma estratégia e possibilidade de negociar com os poderes hegemônicos, o que em certa medida é palpável na história dos movimento e organizações indígenas na Colômbia. Rappaport define interculturalidade como a forma em que os ativistas indígenas se apropriam de conceitos de outras culturas com o objetivo de construir um diálogo intercultural, e a define como radicalmente diferente do multiculturalismo pregado pela Constituição de 1991:

\begin{abstract}
A diferencia del multiculutralismo. La interculturalidad no considera al pluralismo como el simple fenómeno de la tolerancia hacia las minorías, permitiéndoles participar en una democracia representativa que diluye su impacto en la nación. En vez de esto la interculturalidad busca nuevas formas de forjar condiciones de igualdad y consenso mientras amplia las voces minorítarias. La interculturalidad va más allá del multiculturalismo en la medida que implica más que un encuentro enmarcado por relaciones hegemónicas. Procura en cambio crear nuevas relaciones horizontales dentro del paradigma de un Estado pluralista. Más aun la interculturalidad introduce la diferencia cultural en el llamado izquierdista a favor de un pluralismo político radical. la interculturalidad es un proyecto emergente. No una realidad existente. (RAPPAPORT, 2008, p. 153)
\end{abstract}

\title{
6. Problematizando a interculturalidade
}

Nesse sentido, para Eduardo Restrepo o conceito de interculturalidade ainda que a primeira vista pareça algo positivo, na realidade possui diferentes complexidades:

La noción de interculturalidad requiere de una labor teórica que evidencie sus limitaciones y alcances. No es gratuito, entonces, que se comience por evidenciar lo problemático de la categoría de 'cultura' que opera tácita o explícitamente en muchos discursos de la interculturalidad. El argumento central es que la interculturalidad debe escapar a los límites de la culturalización de la imaginación teórica y política dominantes en nuestra época y que operan a partir de cierta otrerización de la diferencia (RESTREPO, 2014, p.11). 
A crítica que Restrepo faz ao discurso conceitual da inter-culturalidade parte de analisar as limitações e alcances dos dois componentes do termo. Por um lado, o prefixo In que não supõem as dificuldades da interação social é um diálogo que em certos contextos não permite evidenciar as relações assimétricas de poder e conflito nesses intercâmbios sociais. E por outro lado, a culturalidade remete a um ato reducionista e quase fetichista da cultura. Neste sentido, o autor assinala a importância de analisa-los separadamente, encontrando e problematizando os usos teóricos e políticos do conceito. Para ele, esta problematização leva a pensar a interculturalidade desde redutibilidades ou potencialidades. Estas redutibilidades têm a ver primeiro com a relação entre cultura e culturalismo (RESTREPO, 2014, p. 21) Nesse sentido, o antropólogo colombiano fala de certo reducionismo culturalista, que opera no uso político e conceitual da interculturalidade, definindo três registros em que isso se identifica: 1 . A cultura como curinga narrativo. 2. A cultura como recurso econômico e simbólico. 3. A cultura como objeto de luta, como terreno de disputa e como tecnologia de governo. Para Restrepo, o grau de essencialismo incorporado pelo culturalismo e pela otrerización da diferença ressalta o encerramento das práticas e discursos da interculturalidade na medida em que é necessária certa desnaturalização da representação da indianidade ou etnicidade. Em outro sentido, Restrepo também assinala certas potencialidades do discurso intercultural. Destacando: 1) A capacidade de questionamento e crítica a posições universalistas, eurocêntricas e colonizadoras e 2) A importância da ênfase na lógica da heterogeneidade, da diversidade e da diferença como constituintes da conformação social. Em síntese, retomando os estudos de Foucault e Stuar Hall e seu pensamento em torno da identidade, Restrepo considera que a interculturalidade deve ser analisada com a lupa crítica de seus variados significados conceituais e políticos em diferentes contextos históricos:

\begin{abstract}
Metodológicamente, entonces, se examinaría desde un encuadre contextual y de historización no solo lo qué se ha hecho en nombre de la interculturalidad, sino también lo que ha producido e imposibilitado. Siguiendo a Foucault, antes que la pregunta por el qué es la interculturalidad (esto es, buscar una definición esencialista) la pregunta relevante es por el cómo se ha nombrado, qué se ha hecho y cuáles efectos en el mundo de la vida social y las subjetividades. Esto es pasar de una estrategia que hace énfasis en lo definicional o metafísico (que es) hacia un enfoque metodológico que aborda la interculturalidad como históricamente situada y contextualmente producida. De un gesto especulativo y de elucubración mental que identificaría idealmente lo que es y no es interculturalidad, pasar a concretos que apelan al contextualismo radical-historización (RESTREPO; 2014, p. 27).
\end{abstract}

\title{
7. Entre a Violência e o Multiculturalismo (a modo de conclusão).
}

Em 1996 várias organizações indígenas tomaram a sede da Conferência Episcopal na cidade de Bogotá para exigir o cumprimento de seu direito à administração de seus territórios, 
a consulta prévia diante dos projetos de extração de recursos naturais e o reconhecimento de seus direitos fundamentais no marco do conflito armado:

\begin{abstract}
Cuando se cumplen cinco años de promulgada la nueva constitución política, las organizaciones de los pueblos indígenas de Colombia denunciamos con alarma: Que el desarrollo constitucional y legislativo avanza por el camino de las imposiciones, las medida inconsultas, y el recorte de los principios y derechos fundamentales relativos a la diversidad étnica del país. -que los proyectos de infraestructura y de explotación minera y energética se siguen aceptando, se aprueban y ejecutan, desconociendo nuestro derecho a decidir autónomamente y a vivir nuestra identidad con dignidad, violando así nuestros derechos humanos, la constitución y los derechos internacionales; -que los grandes problemas de tierras, educación, derechos humanos, biodiversidad, no solo son desatendidos, sino que se acentúan con la acción y omisión del gobierno; -que al contrario de fortalecerse nuestra autonomía como pueblos se evidencia, una mayor injerencia, de algunas dependencias del Estado en nuestras comunidades ${ }^{9}$.
\end{abstract}

Além destas denúncias das 30 organizações regionais, em sua maioria de zonas selváticas do país, pedem uma reorientação das políticas estatais no caso indígena. Esse ato da tomada da sede do arcebispado em Bogotá por cerca de uma semana gera relevância dentro da imprensa nacional, pressionando para que o Estado junto à diligência indígena pudesse resolver o assunto. Esta ação coletiva colocou em debate e evidência os conflitos entre as organizações indígenas e as distâncias de seus representantes naturais, os novos senadores indígenas. Laurent (2012) analisa e discute os verdadeiros avanços da CP de 1991 em matéria de direitos étnicos e a participação eleitoral dos dirigentes indígenas. De acordo a isto colocou em evidência os dilemas da nação multicultural na última década:

Um dos dilemas é o assunto do território indígena já legitimado e reconhecido como propriedade coletiva indígena. $\mathrm{O}$ Estado cria leis para que os indígenas administrem as terras de acordo com suas diretrizes, reconhece sua autoridade e autonomia em sua administração, mas na prática o Estado não os protege nem muito menos os recursos ali contidos, pelo contrário, parecem motivar a extração e exploração dos mesmos, afirmando a propriedade do subsolo e entrando direta ou indiretamente no conflito entre as comunidades e as empresas extrativistas como no caso da comunidade U'wa e da empresa Oxy em $1993^{10}$. O modelo multicultural fez o Estado se transformar, ao menos em seus discursos institucionais e de

\footnotetext{
${ }^{9}$ Organización de pueblos indígenas amazónicos de Colombia OPIAC. Comunicado a la opinión publica 25 de julio de 1996.

${ }^{10}$ El 26 de octubre de 1991 la Empresa Colombiana de Petróleos empresa estatal colombiana que rige la industria petrolera- y la Occidental de Colombia, Inc, OXY firman un contrato de asociación para la exploración y explotación de hidrocarburos, en el llamada bloque Samoré, con una extensión de más de 200.000 hectáreas, ubicada en los departamentos de Arauca, Boyacá y Norte de Santander. Este contrato comprende territorio sagrado U'wa y los resguardos de la comunidad y a los Parques Naturales del Tama y La Sierra Nevada del Cocuy. SERJE, Margarita. ONGs, indios y petróleo: El caso U'wa a través de los mapas del territorio en disputa. Bulletin de l'Institut français d'études andines. Lima, vol 1, n.32, p. 101-131. Abril. 2003.
} 
construção de uma política pública com diferenciação étnica e cultura. Mas na prática essas transformações parecem trazer mais problemáticas do que solução para as questões fundamentais para a sobrevivência das comunidades (HOUGHTON,2008).

Outro dos dilemas da questão multicultural sem dúvidas é o assunto da representatividade da nova diligência indígena. Para alguns analistas, essa crítica da representatividade das organizações étnicas tem a ver com os novos cenários e novas linguagens que surgem na representação e incorporação estatal (Laurent, 2012). Nos últimos anos surgem novos conceitos e linguagens, se constroem alianças e nascem outras relações que precisam de outros conhecimentos, além de problemáticas mais complexas para as organizações indígenas.

Aparecem termos e palavras como Estado-Nação, povo indígena, bilinguismo, interculturalidade, segurança alimentar, etnodesenvolvimento, biodiversidade, multinacionais, extrativismo, etc. Este vocabulário e linguagem leva a transformar as lideranças no interior das comunidades indígenas para uma certa administração ou gestão social, despolitizando e cooptando as lideranças, então aparecem líderes indígenas, dirigentes ou representantes das comunidades diante da sociedade colombiana nos cenários político-legislativos conformados e controlados pelo Estado.

Nestas novas formas de liderança tem desenvolvido outros perigos que vão contra as próprias lutas indígenas, como, por exemplo, uma má compreensão do poder da representação, repetindo práticas clientelistas entre os líderes, os partidos políticos e o Estado ou pouca legitimidade das comunidades locais que dizem representar. Assim, o líder, que para sua comunidade em alguns casos também era o médico tradicional, o capitão de governo próprio, termina convertido num funcionário cooptado pelo Estado. Para Christian Gros (2010) em torno da construção e reconstrução da identidade étnica, em particular a indígena, em seus contextos sociais, culturais e históricos da América Latina e, principalmente, o colombiano. Existe uma politização desta identidade nos âmbito governamentais do neoliberalismo e da globalização que pode diluí-la.

Outro dos dilemas mais importantes no caso do Estado colombiano e que afeta as comunidades indígenas diretamente é o que ter que viver constantemente no conflito políticomilitar em seus territórios, que aumenta exponencialmente no final do século XX e início do XXI. As exigências de um movimento indígena sobre sua propriedade coletiva e autonomia política e jurídica sobre este, estabelecem antagonismos com o governo neoliberal que privilegia os interesses do indivíduo e indica uma abertura econômica em direção ao mercado. 
Apesar de reconhecer juridicamente a categoria de "resguardo", os territórios indígenas sofrem diferentes ameaças e não possuem a proteção que deveriam receber do Estado (HOUGHTON, 2008). Esta Autonomia parcial é o dilema que enfrentam os líderes das organizações indígenas, onde o direito de território inalienável, imprescritível e não rentável reconhecido pelo Estado, não é respeitado.

Esta violência também influiu nas estratégias dos movimentos indígenas para proteger seus direitos. Houghton (2008) aponta que muitos líderes indígenas foram ameaçados, desaparecidos e assassinados nos últimos anos nas mãos de paramilitares, guerrilha e Estado. A ocupação dos atores armados em seu território, recrutando jovens indígenas e perturbando suas formas de vida, e a penetração de interesses económicos como a construção de hidrelétricas em grande escala, a exploração de hidrocarboníferos, a extração de recursos madeireiros, a instalação das monoculturas de plantação, como a palma africana ou a coca para o narcotráfico, afetam gravemente os modos de vida e suas particularidades culturais; seus territórios se tornaram espaços de confinamento e desarraigo. Isso tem causado o deslocamento forçado de milhares de indígena aos centros urbanos. Esse marco de direitos formais que a CP de 1991 supôs, dista muito de ser uma realidade para as comunidades no que se refere à sobrevivência. À persistência de graves problemas como a usurpação de seus territórios por parte de colonos, proprietários de terra e narcotraficantes, se soma a implementação de projetos de desenvolvimento ou empresas extratoras de recursos, que afetam e diminuem cada vez mais a qualidade dos nichos ecológicos permitem sua sobrevivência, fazendo com que não se cubram necessidades básicas como saúde, educação, alimento e moradia, que somados à agressão física e cultural permanentes exercidas pelas instituições do Estado, da igreja e das missões religiosas internacionais, dos colonos, proprietários de terra, narcotraficantes, guerrilha, exército, ameaçam a sobrevivência, convertendo seus territórios em zonas de guerra e de conflito no marco de um Estado colombiano bipolar que orgulhosamente se nomeia multiétnico e pluricultural a partir da Constituição de 1991. A década de 1990 foi testemunha do nascimento de um Estado multicultural, que surgiu no espírito otimista e esperançador que marcou a ANC, mas como observava em 2001 Lorenzo Muelas, importante liderança constituinte indígena: "esse otimismo para o MIC se diluiu entre as leis de papel e a realidade da violência na Colômbia".

Por outra parte, esse mesmo dilema da violência e as leis estruturou um movimento indígena que emergiu localmente e se fez visível a nível nacional, mas, que, ao final do século 
XX parece subordinado e desaparecido na cooptação e violência por parte dos atores armados, incluindo o próprio Estado colombiano.

\section{Referências}

ANDRADE, Luis. 25 años de la ONIC, un legado vivo de la resistencia indígena en Colombia. In: Revista Observatorio étnico Cecoin. Bogotá, agosto 2007.

ARCHILA Mauricio. Entre pacto y pacto. In: Idas y venidas. Vueltas y Revueltas. Protestas sociales en Colombia. 1958-1990. Bogotá: ICANH, 2005.

ARCHILA NEIRA, Mauricio; GONZÁLEZ PIÑEROS, Nidia Catherine. Movimiento indígena Caucano: Historia y política. Tunja: Editorial Universidad Santo Tomas, 2010.

BARTH, Fredrik. Los grupos étnicos y sus fronteras: La organización social de las diferencias culturales. México: Fondo de Cultura Económica, 1976.

BENGOA, José. La emergencia indígena en América Latina. México: Fondo de Cultura Económica, 2000.

BORRERO, Camilo. Derecho Humanos, multiculturalismo e interculturalidad. In: Multiculturalismo, interculturalidad y derechos humanos. Universidad Libre, Bogotá, 2010.

CAVIEDES, Mauricio. El surgimiento de la Organización Nacional Indígena de Colombia, ONIC en el período de gobierno de Julio César Turbay (1978-1982). In: Colombia Etnias Y Política, Bogotá, v.4 n.1, p.142-159, jun. /jul. 2007.

COLOMBIA, Constitución (1991). Constitución política de Colombia. Gaceta Constitucional número 114 del jueves 4 de julio de 1991 .

CRUZ RODRÍGUEZ, Edwin. Multiculturalismo e Interculturalismo. Una lectura comparada. In: Cuadernos Interculturales. Bogotá, vol 11, n. 20, p. 45-76, ene/jun. 2013.

DELGADO MAHECHA, Ovidio. Debates sobre el espacio en la geografía contemporánea. Bogotá: Editores Universidad Nacional de Colombia. 2003.

GROS, Christian. Colombia indígena. Identidad cultural y cambio social. Bogotá: Fondo Editorial CEREC, 1991.

GROS, Christian. Etnicidad, Violencia y Ciudadanía. In: Nación, identidad y violencia: el desafío latinoamericano, Bogotá: Universidad Nacional de Colombia; Universidad de Los Andes, 2010.

HERREÑO, Ángel. Evolución política y legal del concepto de territorio ancestral indígena en Colombia. Revista El otro derecho, Bogotá, n.32, p. 255, agt. /set. 2004.

HOUGHTON Juan Carlos. Desterritorialización y pueblos indígenas. In: HOUGHTON, Juan Carlos (editor). La tierra contra la muerte. Bogotá: CECOIN, 2008 
JARAMILLO J, Efraín. Los indígenas colombianos y el Estado. Desafíos ideológicos y políticos de la multiculturalidad. Colombia. Editorial: IWGIA 2011.

LAURENT Virginie. Multiculturalismo a la colombiana y veinte años de movilización electoral indígena: circunscripciones especiales en la mira. Revista análisis político. Bogotá, $\mathrm{n}^{\mathrm{o}}$ 75, p. 47 -65. may. /agos. 2012.

MUELAS HURTADO, Lorenzo. La fuerza de la gente: Juntando recuerdos sobre la terrajería en Guambía-Colombia. Bogotá: ICANH, 2005. p. 24-28.

MUELAS HURTADO, Lorenzo. Os povos indígenas e a Constituição da Colômbia: primeira experiência de participação indígena nos processos constituintes da América Latina. In: RAMOS, Alcida Rita (Org.). Constituições nacionais e povos indígenas. Belo Horizonte: Ed. UFMG, 2012, p. 36-52.

QUIJANO, Aníbal. Colonialidad del poder, eurocentrismo y América Latina. In: LANDER Edgardo (Comp.): La colonialidad del saber: eurocentrismo y ciencias sociales. Perspectivas latinoamericanas. Buenos Aires: CLACSO. 2000.

QUIJANO, Aníbal. Colonialidad del poder, globalizacion y democracia. In: Utopías, nuestra bandera: revista de debate político. Buenos Aires, N. 188, 2001.

RAPPAPORT, Joanne. Los colaboradores. Los Retos del pluralismo en un movimiento intercultural. In: Utopías Interculturales. Intelectuales públicos, experimentos con la cultura y pluralismo étnico en Colombia. Popayán: Editorial Universidad del Cauca, 2008.

RESTREPO, Eduardo. Teorías contemporáneas de la etnicidad: Stuart Hall y Michel Foucault. Popayán: Universidad del Cauca, 2004.

RESTREPO, Eduardo. Interculturalidad en cuestión: Cerramientos y potencialidades. En Revista Ámbito de encuentros. Buenos aires, Volumen 7, Número 1, p. 9-30, 2014.

SERJE, Margarita. ONGs, indios y petróleo: El caso U'wa a través de los mapas del territorio en disputa. Bulletin de l'Institut français d'études andines. Lima, vol 1, n.32, p. 101-131. Abril. 2003.

VASCOU, Luis. Quintín Lame: Resistencia y liberación. Revista Tabula Rasa. Bogotá, n.9, p. 73-101, jul./dic. 2008.

VAZQUEZ CARRIZOSA, Alfredo. Historia critica del Frente Nacional. Bogotá: Ediciones Foro Nacional por Colombia, 1992. p. 63-111.

WALSH, Catherine. Interculturalidad y Colonialidad del Poder, In: El Giro Decolonial. Reflexiones para una diversidad epistémica más allá del capitalismo global. Bogotá: Siglo del Hombre Editores; Universidad Central, Instituto de Estudios Sociales Contemporáneos y Pontificia Universidad Javeriana, Instituto Pensar. 2007 